\title{
Non-causal understanding with economic models: the case of general equilibrium*
}

\author{
Philippe Verreault-Julien ${ }^{\dagger}$
}

1st of June 2017

\begin{abstract}
How can we use models to understand real phenomena if models misrepresent the very phenomena we seek to understand? Some accounts suggest that models may afford understanding by providing causal knowledge about phenomena via how-possibly explanations. However, general equilibrium models, for example, pose a challenge to this solution since their contribution appears to be purely mathematical results. Despite this, practitioners widely acknowledge that it improves our understanding of the world. I argue that the Arrow-Debreu model provides a mathematical how-possibly explanation which establishes claims of mathematical dependence. The account developed reveals how mathematical knowledge can inform claims about the world, allow 'what-if-things-had-been-different' inferences, and thus improve our understanding.
\end{abstract}

\section{Introduction}

The puzzle of model-based understanding is the following: how can models that seemingly misrepresent reality provide understanding? This general puzzle, which has also being called the "explanation paradox" (Reiss 2012), is an enduring one in the literature on models across scientific disciplines (e.g. Bokulich 2011; Graham Kennedy 2012; Grüne-Yanoff 2013a; Batterman and Rice 2014; Kuorikoski and Ylikoski 2015; Rice 2015), and especially in economics. The issue originates in the close relationship between explanation and understanding. Indeed, the received view is that having an explanation is a sufficient and necessary condition

*I would like to thank audiences at the EIPE PhD and CHESS seminars and to those at the INEM 2015, Models and Simulation 7, and 3rd International Conference Economic Philosophy conferences for helpful comments. I also wish to express my gratitude to Melissa Vergara Fernández, Rui Francisco de Souza Só Maia, James Grayot, and to the two anonymous referees of this journal for extensive and valuable suggestions on earlier versions of this paper.

$\dagger$ Erasmus Institute for Philosophy and Economics, Erasmus University Rotterdam. Email: verreaultjulien@fwb.eur.nl. I acknowledge support from the Fonds de recherche Société et culture - Québec. 
for having understanding, and that explanations are factive, i.e., they give an account of the explanandum that corresponds to the facts (Trout 2007; de Regt 2009; Khalifa 2012; Strevens 2013). ${ }^{1}$ Thus, good explanations are considered to provide understanding of phenomena of interest. However, a problem arises when our main suppliers of explanations are models since it is contentious whether they satisfy the factivity requirement. This is because models misrepresent reality in many respects by containing assumptions that are descriptively false of reality. Yet, they seem to afford understanding even though the latter can only be provided by models that faithfully represent, or true explanations.

In this paper I am concerned with economic models in particular. Whether economic models explain economic phenomena and thus provide understanding is a contentious debate (e.g. Hausman 1992; Alexandrova 2008; Grüne-Yanoff 2009; Mäki 2009; Sugden 2009; Rice and Smart 2011; Reiss 2012; Alexandrova and Northcott 2013; Hindriks 2013; Kuorikoski and Ylikoski 2015; Ylikoski and Aydinonat 2014). Some proposals suggest that economic models afford understanding by way of providing some form of how-possibly explanations (e.g. Aydinonat 2007; Grüne-Yanoff 2009; Grüne-Yanoff 2013b; Rohwer and Rice 2013; Ylikoski and Aydinonat 2014). The basic idea is that how-possibly explanations, while not actually explaining anything, still provide causal knowledge that affords understanding. For instance, a model may show a possible cause of a phenomenon. Prima facie, it seems such accounts are successful in solving the puzzle of model-based understanding. However, even if those accounts are correct for some cases, it remains an open question whether economic models may afford understanding when they neither provide actual nor possible causal knowledge.

Kenneth Arrow and Gérard Debreu's (1954) seminal ${ }^{2}$ model of general equilibrium therefore poses an interesting challenge to philosophical and methodological accounts of economic models. Since the model's main contribution is a purely mathematical result, viz. two theorems of existence, it seems we should conclude that the model can't afford understanding of economic phenomena. And yet, it does provide understanding according to economists, despite not providing a causal account of the economy.

Not only have Debreu's works contributed to mathematical economics; they have contributed to the science of economics as a whole. [...] Even today, the conceptual framework offered by general equilibrium analysis is continuing to add to our understanding of economic phenomena-and sometimes showing us how little we really understand (Varian 1984, 4-5).

\footnotetext{
${ }^{1}$ For non-factive accounts of explanation see, e.g., Fraassen (1980) and Cartwright (1983).

${ }^{2}$ That Arrow and Debreu made a significant contribution to economics is rarely disputed from within the discipline. The public recognition and the amount of followers their work gathered are momentous. They are both laureates of the Sveriges Riksbank Prize in Economic Sciences in Memory of Alfred Nobel. Arrow and Debreu (1954) is considered the "centerpiece" of the formalist revolution of the 1950s in economics (Blaug 2003).
} 
Who can read them [Arrow-Debreu] without finding their understanding of market power and the role of markets deepened (Hahn $1985,20) ?$

Therefore, whether you are a student, an economic writer, a journalist, a policymaker, or an interested citizen, if you want to understand modern macroeconomics, you have to have passing familiarity with the basic structure and properties of the ADM [Arrow-Debreu-McKenzie model $\left.^{3}\right]$ model [...] (Athreya 2013, 33).

But it was not until long afterward that this system of equations [Walras's] was scrutinized to ascertain whether it had an economically meaningful solution, i.e., whether this theoretical structure of vital importance for understanding the market system was logically consistent (Nobelprize.org 2014).

From the perspective of economics, that the Arrow and Debreu (1954) model made a major contribution to understanding has clear support. However, their work was also the target of very harsh criticisms from economic methodologists, economists, and philosophers alike. Commenting on the type of economic research Arrow-Debreu contributed to establish, Mark Blaug said that "[t]he result of all this is that we now understand almost less about how actual markets work, than did Adam Smith or even Léon Walras" $(2002,38-39) .{ }^{4}$ There is, to say the least, an enormous discrepancy between considering the Arrow-Debreu model worthy of receiving two Nobel prizes and considering that we now understand less. The de facto significance of their work is at odds with some of its critical appraisal. Following the Arrow-Debreu model, do we understand less, or more?

I purport to answer this question. Using a recent account of model-based understanding (Ylikoski and Aydinonat 2014), I offer an example of theoretical modelling that yields knowledge of non-causal dependence. More precisely, I argue that the Arrow-Debreu model provides knowledge of mathematical dependence and affords understanding. Basically, the model shows that, provided certain assumptions are made concerning a competitive economy, there exists a solution to the set of equations, thereby proving the existence of a general equilibrium. The model, while not exhibiting any actual nor even possible causal factors, nevertheless establishes mathematical results that solved a longstanding puzzle of economic theory. These results indicate how the solution mathematically depends on the assumptions made. In short, the model provides a how-possibly mathematical explanation of the general equilibrium. This howpossibly explanation, I argue, affords understanding not only of the model itself, but also of the world. The account developed reveals how mathematical

\footnotetext{
${ }^{3}$ McKenzie (1954) also provided a proof of the existence of a general equilibrium. He also used Kakutani's (1941) theorem, but his result was less general because assumptions were made on demand functions instead of preferences (Geanakoplos 2008).

${ }^{4}$ Hands $(2001,294)$ also reports that for economic methodologists with Lakotosian leanings, general equilibrium theory perfectly exemplifies the problems of contemporary economics.
} 
knowledge can inform claims about the world, allow "what-if-things-had-beendifferent' inferences, and thus improve our understanding.

In what follows, section 2 traces the origins of the general problem Arrow-Debreu addressed. In section $3 \mathrm{I}$ briefly present the model. Section 4 introduces an account of model-based understanding. In sections 5 and 6 I discuss, respectively, why we should consider the Arrow-Debreu model to be a mathematical howpossibly explanation and how it affords understanding of the world.

\section{General equilibrium, from Smith to Arrow- Debreu}

The idea behind the concept of general equilibrium can be traced back to Adam Smith's ([1776] 1904) famous metaphor of the invisible hand (Arrow and Hahn 1971; Arrow 1974; Debreu 1984; Debreu 2008; Geanakoplos 2008). Smith's crucial insight was to see that the unintended consequence of everyone's pursuit of their self-interest can coincide with the promotion of the collective good. Individual participation in the economy, even though motivated by selfinterest, is "led by an invisible hand to promote an end which was no part of his intention" (Smith [1776] 1904, IV.2.9). Explaining social phenomena as being the unintended consequences of individuals' actions has since Smith been a central theme of economics (Ullmann-Margalit 1978; Aydinonat 2008). As a contemporary economics textbook introduces its subject to its readers, "[o]ne of our goals in this book is to understand how this invisible hand works its magic" (Mankiw 2012, 11).

At the time of The Wealth of Nations, Smith's insight was more of a conjecture than anything else (Stiglitz 1991). Indeed, he did not provide any kind of mathematical argument for why we should believe a mechanism or process such as the invisible hand would work in the first place. His argument was very informal and not rigorous by modern standards (Backhouse 1998). As Arrow and Hahn (1971) note, common sense suggests it is impossible to derive social benefit from purely self-interested motives. Yet, the invisible hand hypothesis was sufficiently convincing as to foster further investigations.

The invisible hand hypothesis can be understood as stating that the interaction of individuals in a market economy will result in a situation that is beneficial for all. The modern interpretation ${ }^{5}$ of Smith's invisible hand is the first fundamental

\footnotetext{
${ }^{5}$ Even though some (e.g. Blaug 1996, 60, chap. 1, sec. 31; Backhouse 1997, 128-30; Backhouse 1998, 1853) have pointed out-rightly so-that the precise formulation of the problem that preoccupied Smith underwent a significant transformation under Arrow-Debreu, the fact of the matter remains that practitioners view the general equilibrium model as a significant contribution to the research agenda that Smith set. Smith was much more concerned with the process that leads to market outcomes than with the outcomes themselves. In contrast, as Hahn puts it, "GE [general equilibrium theory] is strong on equilibrium and very weak on how it comes about" $(1984,140)$. See also Blaug $(1992,163)$.
} 
theorem of welfare economics (see Arrow 1951; Debreu 1959), which says that "any competitive equilibrium is necessarily Pareto optimal" (Mas-Collell, Whinston, and Green 1995, 308, emphasis in original). The market for a commodity is in equilibrium when its supply equals its demand. A partial equilibrium is one in which the supply equals the demand in one market. But since prices in one market ultimately depend on prices in other markets, that raises the question whether there is an equilibrium in all markets. The theorem says that a competitive equilibrium, a certain interpretation of a competitive economy where there is an equilibrium in all markets, would lead to a Smith-like situation where private interests mutually coincide. Crucially, the theorem says that if there is such a thing as a competitive equilibrium, then it will be Pareto optimal. However, whether such an equilibrium can actually exist is a deeply related but separate question. For if the equilibrium could not exist, then it would be a significant blow to the invisible hand hypothesis. If the economy can't reach equilibrium, it is more difficult to maintain that exchange in a market economy can come to a point where both producers and consumers are content. A major issue stemming from Smith's idea therefore concerns the existence of equilibrium insofar as the first fundamental theorem of welfare economics suggests that there is indeed such an equilibrium.

An important first step into making the equilibrium argument more rigorous was made by Léon Walras ([1926] 1954) in his Elements of Pure Economics. ${ }^{6}$ Whereas Smith's argument was essentially informal, Walras constructed a mathematical model. According to Debreu (2008), only a mathematical model such as Walras's could fully account for the interdependence of all the variables a general equilibrium presupposes. As Debreu explains, Walras's model still did not answer a fundamental question concerning the general equilibrium, i.e., whether such an equilibrium existed or not. The model rather assumed that there was a set of prices and quantities where supply would equal demand. The main argument supporting that belief was to count the equations and the unknowns in the model and to observe that they were in equal number (Debreu 2008). ${ }^{7}$ But as Debreu noted, that argument was in no way definitive. In other words, it was not a proof. Yet, it was common belief that the equilibrium-the set of prices and quantities where markets clear-could exist despite the absence of a definitive proof. Arrow and Hahn (1971) explicitly link investigations of general equilibrium to the need to logically analyze the idea that uncoordinated economic action can result in an equilibrium. From Smith onwards there was a widespread belief that something akin to a general equilibrium could in principle exist, but that belief was not fully warranted. The question of the existence of the equilibrium was therefore by and large unanswered. The Arrow-Debreu model was a seminal contribution to answering this question. The existence problem only found a definitive solution with Arrow-Debreu's proof. Arrow and Debreu (1954) "appeared to bring closure

\footnotetext{
${ }^{6}$ The book was originally published in French in 1874

${ }^{7}$ Blaug (1996, chap. 13) notes that Walras also tried to show by which mechanism the equilibrium could actually be achieved-the tâtonnement process-which in a sense can also be an argument in favour of the existence of general equilibrium.
} 
to an argument that was at least two centuries old" (Weintraub and Gayer 2001, 421).

\section{The Arrow-Debreu model}

Arrow and Debreu (1954) is a paradigmatic example of a mathematical model in economics. It is highly mathematical and its connection to real-world phenomena appears to be indirect. Its main results "are two theorems stating very general conditions under which a competitive equilibrium will exist" (Arrow and Debreu 1954, 266). To establish these results, Arrow-Debreu use the axiomatic method. Essentially, the axiomatic method consists in building a mathematical system from basic propositions or postulates, namely the axioms. The axioms are taken as the building blocks of the system and they are then used to deductively derive the theorems, i.e., propositions that are not as basic as the axioms but are logically entailed by them. The system thus built has a "mathematical form that is completely separated from its economic content" (Debreu 1986, 1265). ${ }^{8}$ The logical consistency of the mathematical structure is independent of its economic interpretation.

Using the axioms, some additional assumptions, and mathematical techniquese.g. rules of inference-they can make deductions about the logical properties of the system, deductions that are, we should repeat it, in principle independent of any empirical content. Arrow-Debreu define a competitive equilibrium as one that satisfies four conditions, where $R^{l}$ is the set of all vectors with $l$ components, $y_{j}$ denotes a production plan for the production unit $j$ in the set $Y_{j}$ of production plans, $x_{i}$ the consumption $x$ of a consumption unit $i$ in the set $X_{i}$ of consumption vectors, $u_{i}\left(x_{i}\right)$ the utility derived for unit $i$ from consuming $x, z$ is a vector whose components are the excess demand over supply for the commodities, and the asterisks $\left(^{*}\right)$ equilibrium values, e.g., $p^{*}$ is an equilibrium price vector. ${ }^{9}$

1. $y_{j}^{*}$ maximizes $p^{*} \cdot y_{j}$ over the set $Y_{j}$, for each $j$ (Arrow and Debreu 1954, 268)

2. $x_{i}^{*}$ maximizes $u_{i}\left(x_{i}\right)$ over the set $\left\{x_{i} \mid x_{i} \epsilon X_{i}, p^{*} \cdot x_{i} \leqq p^{*} \cdot \zeta_{i}+\sum_{j=1}^{n} \alpha_{i j} p^{*}\right.$. $\left.y_{j}^{*}\right\}(271)$

3. $p^{*} \epsilon P=\left\{p \mid p \epsilon R^{l}, p \geqq 0, \sum_{h=1}^{l} p_{h}=1\right\}(271)$

4. $z^{*} \leqq 0, p^{*} \cdot z^{*}=0(271)$

\footnotetext{
${ }^{8}$ Debreu $(1984,405)$, in his Nobel lecture, similarly explains what is axiomatization and how it was linked to the coordination problem Adam Smith apprehended.

${ }^{9}$ For a more exhaustive description or reconstruction, readers are invited to consult the Arrow and Debreu (1954) paper itself, Weintraub (1983) or Geanakoplos (2008). I am here first and foremost concerned with their methodology and the main results they achieved. The exposition of the model will thus be minimal.
} 
To establish the existence of the equilibrium, Arrow-Debreu first needed to provide precise assumptions about a competitive economy. Conditions 1 and 2 basically express the idea that producers (1) and consumers (2) maximize their profits and utility, respectively. Condition 3 says that prices are non negative and not all zero and condition 4 normalizes prices. Conditions 1 and 2 are the ones most clearly connected to the Smithian idea of individuals pursuing their self-interest. The competitive model formalizes this pursuit since one important motivation behind the model is to see whether it is compatible with a general equilibrium. They then make the following assumptions about the production possibilities and consumers' preferences. Assuming $Y=\sum_{j=1}^{n} Y_{j}$, then $Y$ represents all the possible production plans $Y$ and $(-Y)$ contains the additive inverse components of $Y . \Omega$ is the non-negative orthant of $R^{l}$ (Weintraub 1983, 35 ), i.e., a set for which all components are part of $R^{l}$ and are greater or equal than $0 . u_{i}$ indicates the utility of the $i$ th consumption unit. $\zeta_{i}$ denotes the vector of initial endowment of various commodities held by the $i$ th consumption unit and $\alpha_{i j}$ is a contractual claim to each production unit $j$ 's share of profit.

I.a. $Y_{j}$ is a closed convex subset of $R^{l}$ containing $0(j=1, \ldots, n)$. (267)

I.b. $Y \cap \Omega=0(267)$

I.c. $Y \cap(-Y)=0(267)$

II. The set of consumption vectors $X_{i}$ available to individual $i(=1, \ldots, m)$ is a closed convex subset of $R^{1}$ which is bounded from below; i.e., there is a vector $\xi_{i}$ such that $\xi_{i} \leqq x_{i}$ for all $x_{i} \in X_{i}$. (268)

III.a. $u_{i}\left(x_{i}\right)$ is a continuous function on $X_{i}$. (269)

III.b. For any $x_{i} \in X_{i}$, there is an $x_{i}^{\prime} \in X_{i}$ such that $u_{i}\left(x_{i}^{\prime}\right)>u_{i}\left(x_{i}\right)$. (269)

III.c. If $u_{i}\left(x_{i}\right)>u_{i}\left(x_{i}^{\prime}\right)$ and $0<t<1$, then $u_{i}\left[t x_{i}+(1-t) x_{i}^{\prime}\right]>u_{i}\left(x_{i}^{\prime}\right)$. (269)

IV.a. $\zeta_{i} \in R^{l}$; for some $x_{i} \in X_{i}, x_{i}<\zeta_{i}$; (270)

IV.b. for all $i, j, \alpha_{i j} \geqq 0$; for all $j, \sum_{i=1}^{m} \alpha_{i j}=1$. (270)

To establish whether there could be a general equilibrium, additional assumptions on the production possibilities and preferences of consumers needed to be done. Assumptions I.a-c define the production plans and its constraints, namely that (I.a) production plans are convex, which rules out increasing returns to scale, i.e., productivity gains of adding inputs, that (I.b) it is impossible to get an aggregate production plan without using any input, and that (I.c) two production possibility vectors can't exactly cancel each other, i.e., one's outputs can't equal another's inputs since labor is also necessary and can't be produced. Assumptions II-III.c concern consumption behaviour. Assumption II defines the consumption plans agents can choose from. Assumptions III.a-c posit how agents choose over the consumptions plans: III.a continuity, III.b non-satiation, and III.c convexity of agents' preferences. Assumptions IV.a and IV.b concern the initial endowments. Based on the preceding conditions of a competitive equilibrium and assumptions, they then propose a first theorem, the proposition they need to prove. 
Theorem I. For any economic system satisfying Assumptions I-IV, there is a competitive equilibrium (Arrow and Debreu, 1954, 272).

What the theorem says is that if an (economic) system satisfies assumptions I-IV, then there exists an equilibrium such that it satisfies conditions 1-4 of how they define a competitive equilibrium. Having submitted the theorem, they next proceed to prove it. The proof is purely mathematical. They first show that if there is an equilibrium, then it necessarily satisfies the conditions for a competitive equilibrium. They then demonstrate that the plans the agents choose from satisfy assumptions I-IV and that an equilibrium could be inferred from it, which necessarily is a competitive one. The proof thus demonstrates that assumptions I-IV are sufficient conditions for the existence, as defined, of a competitive equilibrium.

In the fourth part of the article, Arrow-Debreu propose to establish the existence of the equilibrium, but by relaxing the assumption (IV.a) that every agent has a positive amount of every good for trading. They consider this assumption too strong-i.e., unrealistic-and thus want to see if they can derive the same result-the equilibrium-without it. Relaxing the assumption, however, comes "at the cost of making certain additional assumptions in different directions and complicating the proof" (Arrow and Debreu 1954, 280). Basically, they modify assumption IV.a so that IV.a' and IV.b are incorporated in IV' and formulate other ones (V, VI, and VII) to make the relaxation of IV.a possible. I will not enter into the details of these new assumptions because what is ultimately important to note is not the assumptions themselves, but the fact that Arrow-Debreu test the robustness of the existence of the equilibrium under changes of assumptions. Suffice it to say that in effect they now only suppose that agents can supply at least one type of productive labor instead of owning a positive amount of everything.

Theorem II For an economic system satisfying Assumptions I-III, IV', and V-VII, there is a competitive equilibrium (Arrow and Debreu, 1954, 281).

The second theorem is thus essentially the same as Theorem I (the equilibrium exists), but derived from slightly different assumptions. This shows that assumption IV.a is not necessary for the existence of the equilibrium, at least as it was initially formulated in the proof of the first theorem. In the fifth part they prove that Theorem II is true.

I started this section by saying the model was highly mathematical. However, it is not mathematical in the sense that it is idealized and represent causal patterns using an abstract mathematical formalism. It is mathematical, I contend, in the sense that the relevant facts and claims it establishes are mathematical, not causal. Yet, the model also appears to be populated by producers and consumers who act on commodities, production plans, prices, etc. Are not the relationships between these fundamentally causal? As Hahn emphasizes, "[t]he first important point to understand about this construction [Arrow-Debreu equilibrium] is that it makes no formal or explicit causal claims at all" (Hahn 1984, 47). It does not 
claim that actual economies will end up in an equilibrium nor does it describe mechanisms or processes that could generate it. However, it is motivated by what Hahn calls a "weak causal proposition" (47), namely that if a sequence of economic states reach an end state, then it will necessarily be an equilibrium. This is because of the assumed economizing action of agents who will engage in exchanges until no one would prefer a different economic state. Conditions 1 and 2 above convey this weak causal proposition. This simply implies that the axioms and assumptions are not arbitrarily chosen, they are not "plucked out of thin air" (Hahn 1985, 12). That said, as we will see in more details in section 6 , it does not imply that the main contribution of the model is causal. The motivation for the model may have been partly causal, but the results are not.

\section{Model-based understanding and how-possibly explanations}

According to economists, the Arrow-Debreu model affords understanding. Many scholars (see Aydinonat 2007; Grüne-Yanoff 2009; Grüne-Yanoff 2013b; Rohwer and Rice 2013; Ylikoski and Aydinonat 2014) consider that economic models ${ }^{10}$ may afford understanding by providing how-possibly explanations (HPEs thereafter). HPEs are usually contrasted with how-actually explanations. Howactually explanations, contrary to HPEs, give an account of why something is actually the case. A common reason for why HPEs can afford understanding is because they establish claims of causal possibility. However, how can a model afford understanding if it does provide knowledge, but not of the causal sort? To answer this question, let us first look at an account of model-based understanding which I will then use to draw analogies to the Arrow-Debreu case.

Ylikoski and Aydinonat (2014) offer an insightful defence of theoretical modelling in economics that aims to solve the puzzle of model-based understanding. ${ }^{11}$ They argue that HPEs, as illustrated by Thomas Schelling's $(1971 ; 1978)$ widely discussed checkerboard model of residential segregation, provide understanding despite the fact that they do not explain any actual phenomena. ${ }^{12}$ This is because they yield knowledge of causal dependence and allow modellers to answer 'whatif-things-had-been-different' questions ( $w$-questions thereafter) about phenomena of interest. In their account, this knowledge enables the ability to make correct 'what-if' inferences ( $w$-inferences thereafter) about said phenomena. This ability to make inferences about counterfactual scenarios is, according to them, the

\footnotetext{
${ }^{10}$ For a discussion of HPEs in biological sciences, see Brandon (1990), Forber (2010), Forber (2012), Bokulich (2014).

${ }^{11}$ See also Ylikoski (2009), Ylikoski and Kuorikoski (2010), and Kuorikoski and Ylikoski (2015).

${ }^{12}$ Whether HPEs should be classified under the genus 'explanation' or not is a contentious issue (e.g. Forber 2010; Forber 2012; Reydon 2012; Bokulich 2014). That debate is however largely irrelevant to the question discussed here because there is widespread agreement that HPEs can afford understanding.
} 
essential criterion to attribute understanding. ${ }^{13}$ But that ability, crucially, "is based on knowledge about dependences" (Ylikoski and Aydinonat 2014, 29). Having knowledge of counterfactual dependence and being able to use it to answer $w$-questions are jointly sufficient and necessary for understanding. Counterfactual dependence thus provides understanding by virtue of allowing one to answer $w$-questions. Knowing relations of counterfactual dependence enables to see how two variables-or an explanandum and an explanans-are connected, how a change in one makes a difference to the other.

According to Ylikoski and Aydinonat (2014), the checkerboard model is a HPE since it shows a possible cause of residential segregation. They also make a difference between two kinds of HPEs: 'possible causal scenarios' and 'causal mechanism schemes'. On the one hand, possible causal scenarios are potential causal explanations of a given phenomenon. They provide a causal history that, had it taken place, would have brought about the explanandum phenomenon. Causal mechanism schemes, on the other hand, are not meant to explain any particular empirical phenomenon, like residential segregation in, say, Detroit. They are sorts of 'templates' (cf. Sugden 2009) that can apply to many phenomena. Their explanandum is located at a higher level of abstraction and is usually highly stylized. It is characteristic of a type of modelling that Michael Weisberg (2013, chap. 7) calls 'modelling a generalized target'. The checkerboard model offers a causal mechanism scheme about residential segregation in general, not about its specific instantiations. The scheme shows that preferences for not being in a minority status are sufficient to generate segregation inside a checkerboard-type space. Even though it can be related to actual cases of residential segregation, the checkerboard model's main contribution is to show that it could depend on those preferences: "it expands the menu of possible explanations of a wide variety of segregation processes" (Ylikoski and Aydinonat 2014, 30). Establishing that residential segregation does not necessarily depend on strong discriminatory preferences thus illuminates facts about the real world by disproving the impossibility thesis that other types of preferences could lead to segregation (Reiss 2008; Grüne-Yanoff 2009).

To say that a model affords understanding is to say that a model allows one to answer $w$-questions. Suppose that a case of residential segregation is effectively caused by strong discriminatory preferences. Knowing that preferences for not being in a minority status can bring about residential segregation allows us, for instance, to answer the following $w$-question: 'What if individuals did not have discriminatory preferences?' Based on our knowledge, we are able to make the following $w$-inference: 'Residential segregation could still occur.' The checkerboard model establishes that segregation does not necessarily depend on strong discriminatory preferences, but rather depends on a broader range of

\footnotetext{
${ }^{13}$ Their account has many commonalities with Woodward's (2003) theory of causal explanation. Woodward claims that explanations "provide understanding by exhibiting a pattern of counterfactual dependence between explanans and explanandum - a pattern of counterfactual dependence of the special sort associated with relationships that are potentially exploitable for purposes of manipulation and control" $(2003,13)$.
} 
preferences. It can therefore allow to infer how changes in preferences relate to changes in segregation.

Ylikoski and Aydınonat provide an account of how HPEs that yield causal knowledge afford understanding. They emphasize the role of causal dependence in providing understanding. This is to be expected since the literature on scientific explanation, and thus on scientific understanding, has been predominantly interested in causal explanations (e.g. Lipton 2004; Salmon 1984; Strevens 2008; Woodward 2003). But Ylikoski and Aydınonat also do not explicitly rule out cases of non-causal dependence. In fact, in other works Ylikoski explicitly recognizes that other types of dependence may afford understanding (Ylikoski and Kuorikoski 2010; Ylikoski 2013; Kuorikoski and Ylikoski 2015). Even theories of explanation primarily targeted at causal explanations acknowledge the possibility of non-causal ones (e.g. Strevens 2008, sec. 5.7; Woodward 2003, 220-21). Thus, there is support to the crucial idea that the kind of knowledge one needs to have understanding is knowledge of relations of dependence, be they causal or non-causal. ${ }^{14}$

\section{A mathematical how-possibly explanation}

Having discussed the proposal that knowledge of relations of dependence obtained through HPEs may afford understanding, we can then ask whether the ArrowDebreu model makes a similar contribution to our understanding of the world. Inasmuch as the checkerboard model affords understanding via a HPE that provides a causal mechanism scheme about residential segregation, I submit the Arrow-Debreu model affords understanding via a HPE that provides knowledge of mathematical dependence about the general equilibrium.

\subsection{Mathematical explanations}

To say that the Arrow-Debreu model is a mathematical HPE raises an immediate issue: What is it to mathematically explain empirical phenomena? That mathematical facts can afford understanding by way of explaining phenomena has recently received a lot of attention (e.g. Batterman 2010; Bueno and Colyvan 2011; Lange 2013; Pincock 2007; Pincock 2015). ${ }^{15}$ While there are still many

\footnotetext{
${ }^{14}$ The idea that knowledge of dependence in general is a central-or at least very importantelement of understanding is also suggested outside the narrowly construed philosophy of science literature (e.g. Kim 1994; Greco 2014; Grimm 2014).

${ }^{15}$ At first sight, it may appear that Sober's (1983) account of equilibrium explanation would readily fit the general equilibrium case. However, whether so-called equilibrium explanations are in fact causal is contentious (see e.g. Woodward 2003, 6-7; Kuorikoski 2007; Strevens $2008,267 f f$.$) . Since what I ultimately want to stress is that the HPE involved is essentially$ non-causal, I prefer to remain agnostic towards the exact status of equilibrium explanations. What is important for the point I am making is that non-causal facts, mathematical ones I hold, are responsible for affording understanding of the world.
} 
unresolved questions concerning the exact role of mathematics in scientific explanations, that some scientific explanations explain in virtue of the mathematical facts they cite is widely accepted. ${ }^{16} \mathrm{~A}$ simple and intuitive example recounted by Lange $(2013,488)$ can make this clear.

That Mother has three children and twenty-three strawberries, and that twenty-three cannot be divided evenly by three, explains why Mother failed when she tried a moment ago to distribute her strawberries evenly among her children without cutting any.

In this case, it is ultimately not the physical facts about the mother or the strawberries that explain why the mother failed to distribute them evenly. Out of mathematical necessity, she possibly can't divide evenly twenty-three units of anything by three. One would not explain this impossibility by citing physical facts about strawberries, the children, or what she exactly did when she attempted to divide them. Of course, if the mother had had twenty-four strawberries, then she would have been able to divide them evenly between her three children. In a sense, an explanation of the mother's failure has to cite these facts. Mathematical facts can only provide an actual explanation of phenomena if there is a mapping or correspondence between the mathematical facts and the physical ones (Pincock 2007; Bueno and Colyvan 2011; Bueno and French 2012). But this only shows that mathematical structures and properties can map on physical facts, not that the latter are essentially responsible for the failure. In this example, the relevant facts are rather mathematical, namely that there is no integer that multiplied by three equals twenty-three. The mother failed this time as she and others would also fail every single other time because of this mathematical impossibility. This simple example illustrates quite clearly that mathematical facts can explain empirical phenomena.

One feature of mathematical explanations is thus that they establish necessary conditions for their explanandum (Lange 2013; Pincock 2015). According to Lange, mathematical explanations show why a given explanandum is more than causally necessary. They appeal to facts that are modally stronger than causal information and constrain the causal space of possibility. They do not explain by virtue of "describing the world's network of causal relations in particular, but rather by describing the framework inhabited by any possible causal relation" (Lange 2013, 509). This makes plain why the mathematical facts explain the mother's failure above. Even though her failure depends in a sense on the specific physical facts of the situation, it depends more on the mathematical impossibility. This sort of necessitation encompasses the physical facts that could obtain. This does not imply that a given phenomenon can't also have a causal explanation, but simply that the mathematical facts necessitate it in a way that causal ones can't.

A notable difference between causal and mathematical explanations is that the latter, instead of exhibiting causal dependence between explanans and

${ }^{16}$ One dissenting view is Strevens (forthcoming). 
explanandum, exhibit mathematical dependence. There is nothing mysterious about this latter sort of dependence. Claims of causal dependence can be established by evaluating the truth of counterfactual conditionals of the form 'Had antecedent $A$ been, consequent $C$ would have been' on the background of a set of relevant causal facts. Similarly, to say that $C$ mathematically depends on $A$ simply means that the truth of this counterfactual is evaluated on the background of the relevant mathematical facts. ${ }^{17}$ It is in this sense that the mother's failure depends on the mathematical impossibility of dividing equally twenty-three by three. Had the mother had twenty-four strawberries, then she would have been able to divide them equally by three. It is also in this sense that the existence of the general equilibrium depends on the assumptions of the model. Had the aggregate production set not been convex, thus implying increasing returns to scale (assumption I.a in sec. 3 ), then the equilibrium would not exist. ${ }^{18}$ We can see how this is connected to the account of understanding presented in the previous section. Knowing on what the failure or the equilibrium depend, we understand why it is so. Knowing the mathematical dependence allows to make $w$-inferences about it. We are able to answer a range of $w$-questions on the circumstances under which the mother would fail, or be able, to divide the strawberries, or about the existence of the equilibrium. In other words, we understand.

However, if the mathematical dependence in the strawberries case explains the failure, the same is not true for the Arrow-Debreu model. Indeed, it does not appear to provide an actual mathematical explanation of general equilibrium. It fails to do so for two reasons. Firstly, it seems it does not identify mathematical facts on which the equilibrium would necessarily depend. When mathematical conditions are only sufficient, we can't know only by appealing to them whether a phenomenon depends on them or not. This is because it may depend on another set of sufficient conditions. Knowing that some conditions are sufficient for bringing about a general equilibrium may therefore not be very illuminating for there may be a number of other such conditions. Secondly, it does not identify actual mathematical structures or properties that map onto the world. An actual mathematical explanation of general equilibrium would require identifying that there is a mapping between the mathematical structure and the phenomenon (Bueno and Colyvan 2011; Pincock 2007; Pincock 2012) and showing how the phenomenon depends on some necessary mathematical properties. In the case of the Arrow-Debreu model, it is rather dubious whether there is such a phenomenon as the general equilibrium in the first place and to what extent the conditions for a competitive economy are satisfied.

\footnotetext{
${ }^{17}$ Some accounts go further and reduce all modal notions of necessity and possibility to the epistemology of counterfactual conditionals (Stalnaker 1968; Lange 2005; Williamson 2007; Kroedel 2012).

18 "Convexity really does perform a crucial role in the proof of existence; it is also a very restrictive assumption and empirically very vulnerable" (Feiwel 1987, 52). See also Debreu (2008).
} 


\subsection{A mathematical HPE}

While the Arrow-Debreu model fails to be an actual explanation of general equilibrium, we should view its contribution as being a mathematical HPE. Causal HPEs, such as the checkerboard model, establish claims of causal possibility. Mathematical HPEs establish claims of mathematical possibility. These claims, I contend, may afford understanding of the world. To make sense of the ArrowDebreu model's contribution to understanding, it is first important to keep in mind the nature of the problem that they were trying to solve (see sec. 2). As Rosenberg $(1992,202)$ observes, it was far from obvious that prices and quantities in all markets could be determined simultaneously. Yet, the invisible hand hypothesis was nevertheless sufficiently compelling for economists to believe in it. We can interpret the Walrasian tradition, Rosenberg says, as solving a 'how-possible' problem about the existence of the equilibrium. As Arrow and Hahn put it, "[t]he proposition [the invisible hand hypothesis] having been put forward and very seriously entertained, it is important to know not only whether it is true, but also whether it could be true" (1971, vii, emphasis in original). Prior to Arrow-Debreu, economists not only did not know whether it was true, but also did not know if it could be true. There was no satisfactory answer to this how-possible question. The very possibility of the equilibrium was not demonstrated. Thus, what the Arrow-Debreu model did was not to establish that there is a general equilibrium in actual economies. What it did was establishing its mathematical possibility. It could, under the conditions specified in the model, be true. It is in this sense that the Arrow-Debreu model is a HPE.

However, even if we grant that the Arrow-Debreu model is a HPE, we could say that the relevant modality is not mathematical. The model would indicate how it could causally be true, not mathematically. For instance, one could say that the model showed how interdependent processes of economizing action by consumers and producers could lead to a general equilibrium. While I agree that the Arrow-Debreu model can ultimately bear on causal claims of this sort, it misinterprets the actual problem they were trying to solve and their contribution. The 'how-possible' problem-i.e., the existence of a general equilibrium-was inherently mathematical. Economists simply did not know whether the equilibrium characterization of the economy was formally consistent and admitted of a solution. Economists had already a causal interpretation. They were lacking the mathematical form. The novelty of the Arrow-Debreu model was not to describe unthought-of causal factors or how they interact, but to prove that within a given mathematical framework the equilibrium necessarily exists. The 'how-possible' problem they were aiming to solve was essentially a consistency check: Is there a set of consistent assumptions for which an equilibrium exists? Answering this question was just a very difficult mathematical problem which did not require describing and assessing causal factors. Koopmans makes this point very explicitly: ${ }^{19}$

\footnotetext{
${ }^{19}$ This is also consistent with how Arrow-Debreu motivate the empirical implication of the model: " The investigation of the existence of solutions is of interest both for descriptive and
} 
The test of mathematical existence of an object of analysis postulated in a model is in the first instance a check on the absence of contradictions among the assumptions made. If we assume that not all members of a body of contradictory statements can have empirical relevance, this logical test has to be passed before any question about the relation of a model to some aspect of reality can seriously be raised (Koopmans 1957, 55).

The problem of existence is a mathematical problem, not a causal one. Crucially, the existence theorems, and thus the equilibrium, do not depend on a particular specification or interpretation of causal facts, but on mathematical ones. As Debreu emphasized, there is a "divorce of form and content" (Debreu 1986, 1265) (see also sec. 3 above) between the mathematical structure and its economic interpretation. Following Ylikoski and Aydınonat's (2014) terminology, we can characterize Arrow-Debreu as providing a 'mathematical scheme'. As the checkerboard model does not have a particular target and can be applied to the general phenomenon of segregation, the Arrow-Debreu model lays out a mathematical framework, or template, that can be used to structure and model relationships between variables. It is not about a particular phenomenon, e.g., general equilibrium in Canada, but about general equilibrium in general. It is meant as a template that can be applied to study the properties of equilibrium, or the absence thereof. The various axioms, definitions, assumptions, and theorems of an axiomatic theory help us to represent economic phenomena by providing "an empty schema of "possible realities"" (Ingrao and Israel 1990, 285 , emphasis in original). That schema provides a mathematical framework in principle divorced from its empirical economic interpretation, but a schema that also constrains the economic (causal) space of possibility. For instance, the framework is incompatible with increasing returns to scale on the production side or with the possibility of a Pareto improvement while at equilibrium (Hahn 1984, 6). So while the existence of the equilibrium does not depend on a specific economic interpretation, the mathematical framework also constrains the possible interpretations.

\section{Arrow-Debreu and understanding the world}

\subsection{Understanding the model vs the world}

If we accept that the Arrow-Debreu model is indeed a mathematical HPE, one could still object that it does not provide understanding of the world, but merely of the model. A common distinction made when assessing the epistemic

for normative economics. Descriptively, the view that the competitive model is a reasonably accurate description of reality, at least for certain purposes, presupposes that the equations describing the model are consistent with each other. Hence, one check on the empirical usefulness of the model is the prescription of the conditions under which the equations of competitive equilibrium have a solution" (Arrow and Debreu 1954, 265). 
contribution of models is between understanding the model and understanding the world. One understands the model when one gets a better grasp of the model's implications, how some results are derived, whether some assumptions are robust, etc. Put differently, one understands the model when one knows how its results depend on its assumptions. I take it to be uncontroversial that the Arrow-Debreu model provides such understanding of the model. ${ }^{20}$ But if it is only about the model, then the precedence of the existence question, as expressed by Koopmans $(1957,55)$ in the previous section, would be rather puzzling. It is indeed a question about the model, but whose answer can change the justification we have for certain beliefs about the world. Therefore, it is also, at least indirectly, a question about the world.

The contentious issue is thus how the model also provides understanding of the world. As we have seen earlier, one understands the world when one can make correct $w$-inferences about it. Making correct $w$-inferences requires to have knowledge of relations of dependence. To actually explain a phenomenon implies showing on what it actually depends. The analogy with causal HPEs is once again enlightening. The checkerboard model, for example, does not establish on what residential segregation actually depends. Yet, it is widely claimed that the checkerboard model improved our understanding of the world. Before the checkerboard model, we did not have reasons to believe residential segregation could causally depend on the preferences for not being in a minority status. The model showed it was possible. It is a HPE. Likewise, the Arrow-Debreu model does not show on what the equilibrium actually depends, but rather on what it could depend. In both cases-the checkerboard and Arrow-Debreu models-knowledge of dependence plays a crucial role in warranting beliefs about the world. Asked to commentate in an interview on the relevance of the existence problem, Arrow answered the following: "Therefore, I would like at least to be sure that it is a coherent theory [general equilibrium theory]. That does not prove that the real world is like that, but at least it gives me a chance" $(1987,197)$. The thought is that if it is not possible to provide a consistent mathematical formalization of the general equilibrium, then whether it is an actual empirical phenomenon is unlikely. This is because, as we have seen, claims of mathematical possibility are modally stronger than those about causal possibility. Of course, mathematical possibility does not entail causal possibility. The set of possible mathematical relations of dependence is greater than the set of possible causal relations of dependence. For this same reason, causal impossibility does not entail mathematical impossibility. Some relationships may be causally impossible, yet can be mathematically represented. However, if a phenomenon is causally possible, should it not also be mathematically possible? And if it is mathematically impossible, does it imply that it is also causally

\footnotetext{
${ }^{20}$ In fact, one can find views along these lines from practitioners themselves, for instance: "The question of the existence of a competitive equilibrium is of course a question not about the world but about the model" (Koopmans and Bausch 1959, 120). In a sense, this is obviously correct. When economists prove the existence of a mathematical object within a set of equations, they are at least answering a question about the model.
} 
impossible? As the various practitioners quoted above pointed out in slightly different terms, if one wants to know whether the invisible hand hypothesis is true, an important question one may ask is whether it could be true. They considered that establishing a claim of mathematical possibility would inform them about the world. Thus, Arrow and Debreu (1954) provided a model that improves our understanding of the real world conditions under which we can expect, or not, a general equilibrium.

Backhouse $(1997,133)$ is right to say that our inability to rigorously prove something does not imply it is not true. As a matter of fact, economists' inability to prove the existence of the general equilibrium up until the first existence proofs (e.g. Wald 2017) did not imply that existence was impossible. The existence proof relied on mathematical tools that were developed in the decades before by, among others, Von Neumann (1945) and Kakutani (1941). The theorem by Kakutani was then used by Nash (1950) in order to establish the existence of an equilibrium in a finite game (Debreu 2008). Basically, Arrow and Debreu (1954) used the same mathematical machinery to extend that result to a $n$ th-agent game, the 'economy'. However, economists inability to prove existence can, and was considered to be, evidence against it. Models serve such an evidential role when model-propositions make a difference to justification about world-propositions (Claveau and Vergara Fernández 2015). They do so by strengthening the evidential network one has about these propositions. ${ }^{21}$ For instance, Theorem I in Arrow and Debreu (1954) can contribute to justify the belief that a general equilibrium is causally possible, a belief many economists had, but which was in need of further justification. Conversely, the absence of a proof, or worse, an impossibility proof, could also serve as evidence against its causal possibility. To those who believed it was impossible for the general equilibrium to exist on the ground of mathematical impossibility, Arrow-Debreu showed it was possible. They had to revise their beliefs. And to those who already believed that it was possible, Arrow-Debreu strengthened their existing beliefs. The immediate goal of the model is not to actually explain why there is a general equilibrium in the world, but rather to investigate the conditions under which it could exist. The model establishes mathematical dependence between a mathematical object, the competitive equilibrium, and some assumptions one can make-or has to make-to derive the object. While not actually explaining anything, its particular contribution is the determination of various mathematical conditions, sufficient and/or necessary, for the existence of a general equilibrium. Arrow-Debreu ruled out that it is mathematically impossible for the equilibrium to exist.

\footnotetext{
${ }^{21}$ There is a difference between the checkerboard model as accounted by Grüne-Yanoff (2009) and the Arrow-Debreu model. For Grüne-Yanoff, a change of confidence can only happen when a model 1) presents a credible model that 2) contradicts an impossibility thesis. The Arrow-Debreu model is usually not considered to be credible and it does not contradict an impossibility thesis since many economists already believed that it was possible.
} 


\subsection{Arrow-Debreu and $w$-questions}

However, even if we accept that the Arrow-Debreu model is a mathematical HPE, one could say it remains unclear what $w$-questions about the world it contributes to answer. Since it is a central feature of the account of modelbased understanding presented earlier, this could put pressure on the claim that the Arrow-Debreu model affords understanding of the world. The model established a set of mathematical conditions on which the equilibrium depends. These conditions constrain the space of possibility within which the general equilibrium may receive an empirical interpretation. To give a more concrete example, in Arrow and Debreu (1954) the assumptions are only jointly sufficient for equilibrium, not necessary. However, they are not all equally dispensable. We have already seen the critical role the assumption of convexity has. To give another example, in proving Theorem II, Arrow-Debreu illustrate what kind of $w$-questions their model can allow to answer. Basically, they want to see what assumptions are needed to derive the existence of the equilibrium. They do it by relaxing assumption IV.a, which states that every individual has a positive amount of each commodity. They consider this assumption as "clearly unrealistic" (Arrow and Debreu 1954, 270). The proof of the second theorem, which relies on slightly different assumptions needed to relax IV.a, is an exercise whose goal is to exhibit how the results may change under modifications of the assumptions. It shows that IV.a, at least in its initial form, is not necessary for the existence of the equilibrium. However, whereas having a positive amount of each commodity is not necessary, they assert that "to have equilibrium, it is necessary that each individual possess some asset or be capable of supplying some labor service which commands a positive price at equilibrium" (Arrow and Debreu 1954, 270). Changing the assumptions of the proof reveals how the theorem depends on them and allows one to answer a range of $w$-questions. There is therefore a mathematical dependence relation between the assumptions and the truth of the theorem. But this dependence has implications for empirical interpretations. It allows, for instance, to answer the following $w$-question: 'What if agents had no assets and no possibility to sell their labour at a positive equilibrium price?' One $w$-inference we can make is that there would be no general equilibrium. This is because we know that such an economic interpretation does not instantiate mathematical properties considered necessary for the equilibrium. Answering this $w$-question is only possible because we have knowledge of mathematical dependence. This allows one to answer various $w$-questions about the world. For instance, we would know that if the world did not instantiate some conditions deemed necessary, then a general equilibrium would not, out of necessity, ensue. Conversely, we would know what features of the world would be sufficient to obtain an equilibrium. Uncovering sufficient and necessary conditions for equilibrium thus has the potential to allow us to answer a range of $w$-questions about why the equilibrium exists or not.

Looking at the cluster of models (Rodrik 2015; Ylikoski and Aydinonat 2014) using similar assumptions can also provide a much richer account of what 
relations of dependence are at play and of which ones may be necessary. The checkerboard model, for instance, has been subject to various robustness analyses (see Aydinonat 2008; Muldoon, Smith, and Weisberg 2012) to establish under what conditions segregation patterns can be expected. In similar fashion, the Arrow-Debreu model has now been subject for decades to similar robustness tests (e.g. Arrow and Hahn 1971; Arrow and Intriligator 1982). In particular, under what conditions the equilibrium is unique (are there multiple sets of prices and quantities?) or stable (will an economy out of equilibrium come back to the equilibrium value?) have been topics of intense scrutiny. It was, for instance, a central motivation of Arrow and Hahn to study those abstract mathematical relations of dependence and see "how robust this result [the existence of general equilibrium] is" (1971, vii). One goal of their book was to analyse the various conditions under which general equilibrium would still hold. Later in the same page they justify this practice the following way: "In attempting to answer the question 'Could it be true?', we learn a good deal about why it might not be true" (Arrow and Hahn 1971, vii). Hands (2016) claims that seeing these attempts as derivational robustness analysis (see Woodward 2006; Kuorikoski, Lehtinen, and Marchionni 2010) is an accurate description of the practice. Derivational robustness analysis involves testing the sensitivity of a model's derivationse.g. existence of the equilibrium-to changes of its assumptions. It can allow one to see what role different assumptions play in driving the model's results. Crucially, derivational robustness analysis amounts to asking various $w$-questions about changes of assumptions (Ylikoski 2014; Kuorikoski and Ylikoski 2015). Hands also argues that preliminary successes in robustness analysis increased the credibility of the general equilibrium model. But, Hands notes, failures of robustness in some respects, especially concerning stability, have also reduced confidence in the model as the best characterization of a competitive economy.

One could then object that since the project failed to uncover robust conditions, then the Arrow-Debreu model can't afford understanding. However, as Arrow and Hahn noted above, we can also understand "why it might not be true". As it happens, for economists, the model still has some important benefits in that it "provides us with a clear benchmark against which to measure the dysfunction of the real world [...]" (Athreya 2013, 33). ${ }^{22}$ That the model can serve as a benchmark ${ }^{23}$ supposes that economists are fairly confident that the conditions they have for equilibrium are relevant for studying the actual world, perhaps that they are quasi-necessary or sufficiently good approximations of what would be required in the world. It supposes that the knowledge they have concerning the conditions under which the equilibrium exists can be used, as a matter of fact, to answer w-questions. For instance, it gives a framework in which actual deviations like informational asymmetry can be studied (e.g. Akerlof 1970). Instead of affording understanding why there is a general equilibrium, the model may afford understanding why there is not. Stiglitz assesses in similar terms Arrow-Debreu's contribution. According to him, their achievement was

\footnotetext{
${ }^{22}$ See also Hahn (1973) for a similar justification.

${ }^{23}$ A role that Debreu $(1986,1268)$ recognized.
} 
not to prove that the equilibrium generally exists, but instead it "was to find those special and limiting conditions under which the Invisible Hand theorems hold" (Stiglitz 1991, 18). Since we know that the world does not instantiate certain conditions specified by the model (e.g., some markets have increasing returns to scale), we may understand why there is no equilibrium. What may make the (broadly construed) Arrow-Debreu model suitable as a benchmark is thus not its causal similarity to the actual world, but that it states conditions that economists consider quasi-necessary for the equilibrium. The mathematical relations of dependence constrain sufficiently the economic space of possibility. Despite the lack of similarity to the actual world, the model may therefore allow to make $w$-inferences about real world phenomena. As Hahn aptly puts it, the aim of the model "is not realism but aid to understanding" (1985, 20-21).

Finally, one might-rightfully-worry that any mathematical model could afford understanding of the world. This would indeed be an undesirable consequence. A good account of model-based understanding should be able to discriminate between mathematical models that afford understanding and those that do not. The account presented above offers resources to assess the contribution of models to understanding. The critical constraint it puts is that a model has to allow one to answer $w$-questions about the world, as the checkerboard model does, for instance. However, not all models can allow to answer such questions. For instance, a mathematical relation of dependence that could not receive any relevant empirical interpretation could not be used to answer $w$-questions about the world. Moreover, mathematical relations of dependence that would not constrain at all the space of empirical possibility would simply not exhibit on what a phenomenon depends. Even though the account is in principle liberal regarding what can afford understanding, not anything goes.

More generally, a HPE, causal or mathematical, can be true or false. It can, or fail, to establish possibility claims. Why does the checkerboard model provide understanding of the phenomenon of residential segregation and not, for instance, a HPE that would postulate that, say, unicorns are causally responsible for the phenomenon? It is widely considered that the checkerboard model established a claim of causal possibility. The same would not be true for the HPE relying on unicorns; according to our best causal knowledge, it is not causally possible for unicorns to bring about segregation. One compelling reason why the ArrowDebreu model passes this test-that of offering a true HPE-is that economists by and large regard it as establishing a (true) claim of mathematical possibility. Not all models pass it though. For instance, Walras's ([1926] 1954) model came close, but ultimately fell short of offering the mathematical HPE economists sought. One might object that practitioners can be wrong. This can indeed be the case, but it is also to some extent undesirable for a philosophical account to conflict with sentiments that are widespread in the practice of a science. As Hausman argues, methodologists "should be suspicious of accounts that attribute to economists egregious and persistent errors" $(2009,40)$. That is not to say that philosophy can't criticize economics, but rather that we should be careful before dismissing a scientific practice that appears to afford genuine understanding for 
economists. That the Arrow-Debreu model actually affords understanding of the world is a good explanation of why practitioners consider it does. In turn, that the model provides a mathematical HPE is, I contend, a good explanation of why the model affords said understanding.

\section{Conclusion}

The puzzle of model-based understanding is a significant one. Recent philosophical accounts show that models can afford understanding when they provide causal knowledge via a how-possibly explanation. However, cases where models do not provide that sort of knowledge have so far been left out. One such case is the Arrow and Debreu (1954) model of general equilibrium. The model, in the eye of economists, affords understanding. Using an account of model-based understanding (Ylikoski and Aydinonat 2014) and drawing an analogy with causal how-possibly explanations, I argued that the Arrow-Debreu model is a mathematical how-possibly explanation. Being so, the model provides knowledge of mathematical dependence that can be used to answer various questions about the real world. Viewing the Arrow-Debreu model as providing knowledge of mathematical dependence allows to interpret it as making a genuine contribution to our understanding despite the fact that it does not provide us with knowledge of causal dependence. This interpretation contributes to elucidate partly the discrepancy between the different appraisals of the model's contribution to understanding. The model does not provide causal knowledge, yet its contribution to our knowledge, mathematical in this case, is difficult to dispute. That knowledge, in turn, also affords understanding of the world we live in.

\section{References}

Akerlof, George A. 1970. "The Market for 'Lemons': Quality Uncertainty and the Market Mechanism." Quarterly Journal of Economics 84 (3): 488-500.

Alexandrova, Anna. 2008. "Making Models Count." Philosophy of Science 75 (3): 383-404.

Alexandrova, Anna, and Robert Northcott. 2013. "It's Just a Feeling: Why Economic Models Do Not Explain." Journal of Economic Methodology 20 (3): $262-67$.

Arrow, Kenneth J. 1951. "An Extension of the Basic Theorems of Classical Welfare Economics." In Proceedings of the Second Berkeley Symposium on Mathematical Statistics and Probability, edited by Jerzy Neyman, 507-32. Berkeley: University of California Press. 
_. 1974. "General Economic Equilibrium: Purpose, Analytic Techniques, Collective Choice." The American Economic Review 64 (3): 253-72.

- 1987. "Oral History I: An Interview." In Arrow and the Ascent of Modern Economic Theory, edited by George R. Feiwel, 191-242. Basingstoke: Macmillan Press.

Arrow, Kenneth J., and Gerard Debreu. 1954. "Existence of an Equilibrium for a Competitive Economy." Econometrica 22 (3): 265-90.

Arrow, Kenneth J., and Frank H. Hahn. 1971. General Competitive Analysis. Amsterdam: Elsevier.

Arrow, Kenneth Joseph, and Michael D. Intriligator, eds. 1982. Handbook of Mathematical Economics. Vol. 2. Amsterdam: North-Holland.

Athreya, Kartik B. 2013. Big Ideas in Macroeconomics: A Nontechnical View. Cambridge, MA: MIT Press.

Aydinonat, N. Emrah. 2007. "Models, Conjectures and Exploration: An Analysis of Schelling's Checkerboard Model of Residential Segregation." Journal of Economic Methodology 14 (4): 429-54.

- 2008. The Invisible Hand in Economics: How Economists Explain Unintented Social Consequences. London: Routledge.

Backhouse, Roger. 1997. Truth and Progress in Economic Knowledge. Cheltenham: Edward Elgar.

Backhouse, Roger E. 1998. "If Mathematics is Informal, Then Perhaps We Should Accept That Economics Must be Informal Too." The Economic Journal 108 (451): 1848-58.

Batterman, Robert W. 2010. "On the Explanatory Role of Mathematics in Empirical Science." British Journal for the Philosophy of Science 61 (1): 1-25.

Batterman, Robert W., and Collin C. Rice. 2014. "Minimal Model Explanations." Philosophy of Science 81 (3): 349-76.

Blaug, Mark. 1992. The Methodology of Economics: Or How Economists Explain. 2nd ed. Cambridge: Cambridge University Press.

- 1996. Economic Theory in Retrospect. 5th ed. Cambridge: Cambridge University Press.

- 2002. "Ugly Currents in Modern Economics." In Fact and Fiction in Economics. Models, Realism, and Social Construction, edited by Uskali Mäki, 35-56. Cambridge: Cambridge University Press.

. 2003. "The Formalist Revolution of the 1950s." Journal of the History of Economic Thought 25 (2): 145-56.

Bokulich, Alisa. 2011. "How Scientific Models Can Explain." Synthese 180 (1): 33-45. 
- 2014. "How the Tiger Bush Got Its Stripes: 'How Possibly' Vs. 'How Actually' Model Explanations." The Monist 97 (3): 321-38.

Brandon, Robert N. 1990. Adaptation and Environment. Princeton: Princeton University Press.

Bueno, Otávio, and Mark Colyvan. 2011. "An Inferential Conception of the Application of Mathematics." Nô̂s 45 (2): 345-74.

Bueno, Otávio, and Steven French. 2012. "Can Mathematics Explain Physical Phenomena?" The British Journal for the Philosophy of Science 63 (1): 85-113.

Cartwright, Nancy. 1983. How the Laws of Physics Lie. Oxford: Oxford University Press.

Claveau, François, and Melissa Vergara Fernández. 2015. "Epistemic Contributions of Models: Conditions for Propositional Learning." Perspectives on Science 23 (4): 405-23.

Debreu, Gerard. 1959. Theory of Value. An Axiomatic Analysis of Economic Equilibrium. New Haven; London: Yale Universisity Press.

- 1984. "Economic Theory in the Mathematical Mode." The Scandinavian Journal of Economics 86 (4): 393-410.

- 1986. "Theoretic Models: Mathematical Form and Economic Content." Econometrica 54 (6): 1259-70.

. 2008. "existence of general equilibrium." In The New Palgrave Dictionary of Economics, edited by Steven N. Durlauf and Lawrence E. Blume, 2nd ed., 112-16. Basingstoke: Nature Publishing Group.

de Regt, Henk W. 2009. "The Epistemic Value of Understanding." Philosophy of Science 76 (5): 585-97.

Feiwel, George R. 1987. "The Potential and Limits of Economic Analysis: The Contributions of Kenneth J. Arrow." In Arrow and the Ascent of Modern Economic Theory, edited by George R. Feiwel, 1-188. Basingstoke: Macmillan Press.

Forber, Patrick. 2010. "Confirmation and Explaining How Possible." Studies in History and Philosophy of Science Part C: Studies in History and Philosophy of Biological and Biomedical Sciences 41 (1): 32-40.

- 2012. "Conjecture and explanation: A reply to Reydon." Studies in History and Philosophy of Science Part C: Studies in History and Philosophy of Biological and Biomedical Sciences 43 (1): 298-301.

Fraassen, Bas C. van. 1980. The Scientific Image. Oxford: Oxford University Press.

Geanakoplos, John. 2008. "Arrow-Debreu model of general equilibrium." In The New Palgrave Dictionary of Economics, edited by Steven N. Durlauf and 
Lawrence E. Blume, 2nd ed., 222-32. Basingstoke: Nature Publishing Group.

Graham Kennedy, Ashley. 2012. "A Non Representationalist View of Model Explanation." Studies in History and Philosophy of Science Part A 43 (2): $326-32$.

Greco, John. 2014. "Episteme: Knowledge and Understanding." In Virtues E Their Vices, edited by Kevin Timpe and Craig A. Boyd, 285-302. Oxford: Oxford University Press.

Grimm, Stephen R. 2014. "Understanding as Knowledge of Causes." In Virtue Epistemology Naturalized, edited by Abrol Fairweather, 329-45. Synthese Library 366. Springer International Publishing.

Grüne-Yanoff, Till. 2009. "Learning from Minimal Economic Models." Erkenntnis 70 (1): 81-99.

_. 2013a. "Appraising Models Nonrepresentationally." Philosophy of Science 80 (5): $850-61$.

- 2013b. "Genuineness Resolved: A Reply to Reiss' Purported Paradox." Journal of Economic Methodology 20 (3): 255-61.

Hahn, Frank. 1973. On the Notion of Equilibrium in Economics: An Inaugural Lecture. Cambridge: Cambridge University Press.

-1984. Equilibrium and Macroeconomics. Oxford: Blackwell.

_. 1985. Money, Growth and Stability. Oxford: Basil Blackwell.

Hands, D. Wade. 2001. Reflection Without Rules: Economic Methodology and Contemporary Science Theory. Cambridge: Cambridge University Press.

. 2016. "Derivational robustness, credible substitute systems and mathematical economic models: the case of stability analysis in Walrasian general equilibrium theory." European Journal for Philosophy of Science 6 (1): 31-53.

Hausman, Daniel M. 1992. The Inexact and Separate Science of Economics. Cambridge: Cambridge University Press.

- 2009. "Laws, Causation, and Economic Methodology." In The Oxford Handbook of Philosophy of Economics, edited by Harold Kincaid and Don Ross, 35-54. New York: Oxford University Press.

Hindriks, Frank. 2013. "Explanation, Understanding, and Unrealistic Models." Studies in History and Philosophy of Science Part A 44 (3): 523-31.

Ingrao, Bruna, and Giorgio Israel. 1990. The Invisible Hand: Economic Equilibrium in the History of Science. Cambridge, MA: MIT Press.

Kakutani, Shizuo. 1941. "A generalization of Brouwer's fixed point theorem." Duke Mathematical Journal 8 (3): 457-59. 
Khalifa, Kareem. 2012. "Inaugurating Understanding or Repackaging Explanation?" Philosophy of Science 79 (1): 15-37.

Kim, Jaegwon. 1994. "Explanatory Knowledge and Metaphysical Dependence." Philosophical Issues 5: 51-69.

Koopmans, Tjalling C. 1957. Three Essays on the State of Economic Science. New York: McGraw-Hill.

Koopmans, Tjalling C., and Augustus F. Bausch. 1959. "Selected Topics in Economics Involving Mathematical Reasoning." SIAM Review 1 (2): 79-148.

Kroedel, Thomas. 2012. "Counterfactuals and the Epistemology of Modality." Philosophers' Imprint 12 (12): 1-14.

Kuorikoski, Jaakko. 2007. "Explaining with Equilibria." In Rethinking Explanation, edited by Johannes Persson and Petri Ylikoski, 149-62. Dordrecht: Springer.

Kuorikoski, Jaakko, Aki Lehtinen, and Caterina Marchionni. 2010. "Economic Modelling as Robustness Analysis." British Journal for the Philosophy of Science 61 (3): 541-67.

Kuorikoski, Jaakko, and Petri Ylikoski. 2015. "External representations and scientific understanding." Synthese 192 (12): 3817-37.

Lange, Marc. 2005. "A Counterfactual Analysis of the Concepts of Logical Truth and Necessity." Philosophical Studies 125 (3): 277-303.

. 2013. "What Makes a Scientific Explanation Distinctively Mathematical?" The British Journal for the Philosophy of Science 64 (3): 485-511.

Lipton, Peter. 2004. Inference to the Best Explanation. 2nd ed. London: Routledge.

Mankiw, N. Gregory. 2012. Principles of Macroeconomics. 6th ed. Mason, OH: South-Western, Cengage Learning.

Mas-Collell, Andreu, Michael Whinston, and Jerry Green. 1995. Microeconomic Theory. Oxford: Oxford University Press.

Mäki, Uskali. 2009. "MISSing the World. Models as Isolations and Credible Surrogate Systems." Erkenntnis 70 (1): 29-43.

McKenzie, Lionel. 1954. "On Equilibrium in Graham's Model of World Trade and Other Competitive Systems." Econometrica 22 (2): 147-61.

Muldoon, Ryan, Tony Smith, and Michael Weisberg. 2012. "Segregation That No One Seeks." Philosophy of Science 79 (1): 38-62.

Nash, John F. 1950. "Equilibrium points in n-person games." Proceedings of the National Academy of Sciences 36 (1): 48-49. 
Nobelprize.org. 2014. "The Prize in Economics 1983 - Presentation Speech." http://www.nobelprize.org/nobel_prizes/economic-sciences/laureates/1983/ press.html (accessed 15 September 2015).

Pincock, Christopher. 2007. "A Role for Mathematics in the Physical Sciences." Noûs 41 (2): 253-75.

2012. Mathematics and Scientific Representation. New York: Oxford University Press.

- 2015. "Abstract Explanations in Science." The British Journal for the Philosophy of Science 66 (4): 857-82.

Reiss, Julian. 2008. Error in Economics: Towards a More Evidence-Based Methodology. Milton Park: Routledge.

_. 2012. "The Explanation Paradox." Journal of Economic Methodology 19 (1): $43-62$.

Reydon, Thomas A.C. 2012. "How-Possibly Explanations as Genuine Explanations and Helpful Heuristics: A Comment on Forber." Studies in History and Philosophy of Science Part C: Studies in History and Philosophy of Biological and Biomedical Sciences 43 (1): 302-10.

Rice, Collin. 2015. "Moving Beyond Causes: Optimality Models and Scientific Explanation." Noûs 49 (3): 589-615.

Rice, Collin, and Joshua Smart. 2011. "Interdisciplinary Modeling: A Case Study of Evolutionary Economics." Biology 83 Philosophy 26 (5): 655-75.

Rodrik, Dani. 2015. Economics Rules: The Rights and Wrongs of the Dismal Science. New York: W. W. Norton \& Company.

Rohwer, Yasha, and Collin Rice. 2013. "Hypothetical Pattern Idealization and Explanatory Models." Philosophy of Science 80 (3): 334-55.

Rosenberg, Alexander. 1992. Economics : Mathematical Politics or Science of Diminishing Returns? Chicago: University of Chicago Press.

Salmon, Wesley C. 1984. Scientific Explanation and the Causal Structure of the World. Princeton: Princeton University Press.

Schelling, Thomas C. 1971. "Dynamic Models of Segregation." Journal of Mathematical Sociology 1: 143-86.

. 1978. Micromotives and Macrobehavior. New York: W. W. Norton \& Company.

Smith, Adam. (1776) 1904. An Inquiry into the Nature and Causes of the Wealth of Nations. Edited by Edwin Cannan. 5th ed. London: Methuen \& Co.

Sober, Elliott. 1983. "Equilibrium Explanation." Philosophical Studies 43 (2): 201-10. 
Stalnaker, Robert C. 1968. "A Theory of Conditionals." In IFS, edited by William L. Harper, Robert Stalnaker, and Glenn Pearce, 41-55. The University of Western Ontario Series in Philosophy of Science 15. Springer Netherlands.

Stiglitz, Joseph E. 1991. "The Invisible Hand and Modern Welfare Economics." Working Paper 3641. National Bureau of Economic Research.

Strevens, Michael. 2008. Depth: An Account of Scientific Explanation. Cambridge, MA: Harvard University Press.

- 2013. "No Understanding Without Explanation." Studies in History and Philosophy of Science Part A 44 (3): 510-15.

- Forthcoming. "The Mathematical Route to Causal Understanding." In Explanation Beyond Causation, edited by Alexander Reutlinger and Juha Saatsi. Oxford University Press.

Sugden, Robert. 2009. "Credible Worlds, Capacities and Mechanisms." Erkenntnis 70 (1): 3-27.

Trout, J. D. 2007. "The Psychology of Scientific Explanation." Philosophy Compass 2 (3): 564-91.

Ullmann-Margalit, Edna. 1978. "Invisible-Hand Explanations." Synthese 39 (2). Springer: 263-91.

Varian, Hal R. 1984. "Gerard Debreu's Contributions to Economics." The Scandinavian Journal of Economics 86 (1): 4-14.

Von Neumann, John. 1945. "A Model of General Economic Equilibrium." The Review of Economic Studies 13 (1): 1-9.

Wald, Abraham. 2017. "On Some Systems of Equations of Mathematical Economics." Econometrica 19 (4): 368-403. Accessed January 23.

Walras, Léon. (1926) 1954. Elements of pure economics: or the theory of social wealth. London: Allen \& Unwin.

Weintraub, E. Roy. 1983. "On the Existence of a Competitive Equilibrium: 1930-1954." Journal of Economic Literature 21 (1): 1-39.

Weintraub, E. Roy, and Ted Gayer. 2001. "Equilibrium proofmaking." Journal of the History of Economic Thought 23 (4): 421-42.

Weisberg, Michael. 2013. Simulation and Similarity. Using Models to Understand the World. Oxford: Oxford University Press.

Williamson, Timothy. 2007. "Philosophical Knowledge and Knowledge of Counterfactuals." Grazer Philosophische Studien 74 (1): 89-123.

Woodward, James. 2003. Making Things Happen. A Theory of Causal Explanation. New York: Oxford University Press. 
Woodward, Jim. 2006. "Some Varieties of Robustness." Journal of Economic Methodology 13 (2): 219-40.

Ylikoski, Petri. 2009. "The Illusion of Depth of Understanding in Science." In Scientific Understanding. Philosophical Perspectives, edited by Henk W. de Regt, Sabina Leonelli, and Kai Eigner, 100-119. Pittsburgh: University of Pittsburgh Press.

. 2013. "Causal and Constitutive Explanation Compared." Erkenntnis 78 (2): $277-97$.

. 2014. "Agent-Based Simulation and Sociological Understanding." Perspectives on Science 22 (3): 318-35.

Ylikoski, Petri, and N. Emrah Aydinonat. 2014. "Understanding with Theoretical Models." Journal of Economic Methodology 21 (1): 19-36.

Ylikoski, Petri, and Jaakko Kuorikoski. 2010. "Dissecting Explanatory Power." Philosophical Studies 148 (2): 201-19. 